\title{
Лесоводственные принципы
}

\section{установления, регулирования и учета комплексной доступности лесов при их содержании и использовании}

\author{
(C) В.И. Желдак
}

Silvicultural principles for the establishment, regulation and accounting of the complex accessibility of forests in their maintenance and use

V.I. Zheldak (All-Russian Research Institute for Silviculture and Mechanization of Forestry)

Based on the analysis of literary sources, stock data of research and development of forestry using the systemic method, fundamental silvicultural solutions are formed to the problem of establishing the complex accessibility of forests (CAF). Taking into account the variety of factors and conditions that significantly limit the possibility of effective implementation of targeted forest management and forest maintenance activities. As a result, a conceptual scheme for the establishment, regulation and accounting of the complex accessibility of forests has been formed. The scheme determines the algorithm for establishing CAF - forestry objects for all or priority-significant types and types of accessibility, allocated according to the relevant factors, reflecting the real level - the category of accessibility for each species, type and in general. This takes into account the different priorities and the possibility of changing ("variability") of the factors and the types of CAF determined by them. Taking into account the increasing ecological value of forests, the identified types and types of CAF are prioritized - from the highest conservation, ecological, socio-ecological - to high - natural reforestation, soil-hydrological and orographic, species-productive, to the traditional moderately high transport, to moderate technical and socio-economic. Depending on the degree of possible and permissible change, the types and the types of integrated forest accessibility they combine are divided into three to five categories of possible variability from high and high to moderate, low and very low. According to the levels of forest accessibility, the regimes of their maintenance and use are established - intensive mono-, multipurpose, moderate-, low-intensity traditional, conservation and restoration types, as well as the systems of silvicultural activities that support them. For the purposes of planning, design of forest maintenance, forest use and forest management, forest zoning according to CAF is carried out by allocating areas of plots with 
the same or prevailing level of accessibility. For each site included in a certain zone, real indicators of the level of accessibility and the regime of forest maintenance - forest use are saved.

Keywords: the establishment and regulation of the integrated accessibility of forests, an accessibletarget regime of forest maintenance, silvicultural systems, the priority and variability of types of forest accessibility

Лесоводственные принципы установления, регулирования и учета комплексной доступности лесов при их содержании и использовании

\section{В.И. Желдак}

На основе анализа материалов литературных источников, фондовых данных исследований и разработок лесоводства с использованием системного метода формируются принципиальные лесоводственные решения проблемы установления комплексной доступности лесов (КДЛ), с учетом разнообразия факторов и условий, существенно ограничивающих возможность эффективного осуществления целевых мероприятий лесопользования и содержания лесов. В результате сформирована концептуальная схема установления, регулирования и учета комплексной доступности лесов. Схемой определяется алгоритм установления КДЛ объектов лесоводства по всем или приоритетно значимым видам и типам доступности, выделяемым по соответствующим факторам, с отражением реального уровня - категории доступности - по каждому виду, типу и в целом. При этом учитывается разная приоритетность и возможность изменения («возможная изменчивость») факторов и определяемых ими видов, типов КДЛ. С учетом возрастающей экологической ценности лесов, выделяемые типы и виды КДЛ по приоритетности распределяются от высшей природоохранной, экологической, социально-экологической к высокой - природной лесовоспроизводительной, почвенно-гидрологической и орографической, породно-продуктивной, к традиционной умеренновысокой транспортной, до умеренной технической и социально-экономической. В зависимости от степени возможного и допустимого изменения типы и объединяемые имивиды комплексной доступности лесов подразделяются на три-пять категорий возможной изменчивости - от высшей и высокой до умеренной, низкой и очень низкой. Соответственно уровням доступности лесов устанавливаются режимы их содержания и использования - интенсивного моно-, многоцелевого, умеренно-, слабоинтенсивного традиционного, консервационно-восстановительного типа, а также обеспечивающие их системы лесоводственных мероприятий. Для целей планирования, проектирования мероприятий по содержанию лесов, лесопользованию и управлению лесами осуществляется зонирование лесов по КДЛ путем выделения территорий участков с одинаковым или преобладающим уровнем доступности. Для каждого включенного в определенную зону участка сохраняются реальные показатели уровня доступности и режима содержания лесов - лесопользования.

Ключевые слова: установление, регулирование, учет комплексной доступности лесов, доступно-целевой режим содержания лесов, лесоводственные системы, приоритетность и возможная изменчивость видов доступности лесов

Желдак Владимир Иванович - заведующий лабораторией лесоводства ФБУ ВНИИЛМ, д-р биол. наук

E-mail: lesvig@yandex.ru

Федеральное бюджетное учреждение «Всероссийский научно-исследовательский институт лесоводства и механизации лесного хозяйства»

141202, Московская обл., г. Пушкино, ул. Институтская, д. 15

Тел. 993-30-54; факс: 993-41-91 


\section{Введение}

Нормативными правовыми документами регламентируется применение определенных целевых видов мероприятий лесоводства и лесопользования, их методов, нормативов, в основном, соответственно состоянию участков леса (объектов лесоводства), отражаемому в их параметрах и характеристиках $[9,17,18$, 20]. В частности, применение методов (форм), видов рубок спелых, перестойных лесных насаждений для заготовки древесины (заменяющих фактически лесоводственные рубки лесовозобновления) - относительно равномерно выборочных, постепенных, сплошных определяется при достижении древостоями (поколениями разновозрастного леса) установленных возрастов рубок, в зависимости от возрастной и пространственной структуры насаждений, наличия подроста, потенциала естественного возобновления в определенных лесотипологических условиях, устойчивости при разреживании (несплошных рубках), а также других характеристик.

Подобный принцип используется и при регламентировании назначения мероприятий рубок ухода (РУ), лесовосстановления и других, т. е. соответственно их состоянию, свойствам, характеристикам объектов лесоводства и целям проведения мероприятий (по существу - изменения этих характеристик до целевых). При этом выбор среди аналогичных или сходных по целевым установкам видов в зависимости от возможности (доступности) их осушествления в конкретных экономических условиях, а также наличия транспортной инфраструктуры, технических средств и технологий, обеспеченности трудовыми ресурсами, как правило, определенно не устанавливается.

Предусмотренное правилами возможное применение отдельных сходных по целевым установкам видов мероприятий в различных условиях доступности их осуществления четко не регламентировано и не гарантирует достижения целевого эффекта. В частности, это относится к регламентированию применения мер возобновления леса (лесовосстановле- ния) - созданием лесных культур, в т. ч. и посадочным материалом с закрытой корневой системой, содействием естественному лесовозобновлению и тем более восстановлением леса за счет естественных природных восстановительных процессов [18]. Без учета конкретных условий доступности осуществления этих мероприятий (природных, хозяйственных, экономических) назначение, проектирование и даже выполнение их с неизбежными нарушениями (недостатками) не гарантирует достижение цели. Регламентируемое правилами заготовки древесины возможное применение длительно-постепенных рубок [17], по существу, вместо добровольно-выборочных (где проведение их экономически невыгодно - недоступно) вообще приводит к отрицательному эффекту (хотя и меньшему, чем при сплошных рубках) в связи с заменой при этом абсолютно разновозрастных насаждений (как правило, целевых для защитных лесов) на одновозрастные.

Системное непротиворечивое регламентирование дифференцированного назначения разных видов и вариантов лесоводственных мероприятий в зависимости от доступности (возможности) их осуществления не обеспечивается также и на стадии лесоустроительного проектирования в рамках использования положений лесоустроительной инструкции [19]. В результате, при отсутствии более или менее определенных (даже на уровне методических положений) установок дифференциации реальной доступности лесов, участков лесов для осуществления на них необходимых лесоводственных мероприятий по охране, защите, воспроизводству и использованию лесов, и по существу, возможности выбора альтернативных по содержанию, сложности, затратности, но сходных по целевым результатам - достигаемым (в определенном диапазоне) целям - вариантов мероприятий, при лесоустройстве проектируется проведение одних и тех же видов мероприятий на всех или на части участков, с учетом экономической (хозяйственной) обеспеченности их проведе- 
ния. Соответственно, многие исключительно необходимые сложные затратные лесоводственные мероприятия, проектируемые в зоне транспортной доступности, не всегда проводятся из-за их относительной экономической недоступности, а за пределами такой зоны они вообще могут не назначаться. К таким мероприятиям можно отнести рубки ухода переформирования лиственно-хвойных осиново-еловых насаждений, где вырубка осинового древостоя может быть даже затратной, а мероприятие в системе воспроизводства леса весьма эффективным.

Фактически существует большая, сложная, но в значительной мере скрытая проблема ведения лесного хозяйства (вероятно, за исключением отношения к природным пожарам в труднодоступных местах, где она явно и остро проявляется в дилемме «тушить-не тушить») - использования системы многоуровневой дифференциации доступности лесов, участков лесов - объектов лесоводства [5], формирования соответствующего разновариантного доступно-целевого режима их содержания и разработки для их поддержания разных по составу доступно-целевых лесоводственных мероприятий и их систем.

Для решения этой проблемы, с учетом имеющихся разработок [5, 6] определяется направление и планируемый результат данного этапа исследований - формирование исходных концептуально-методологических принципов достижения цели, которые можно будет реализовать в конкретных нормативнометодических системах установления многофакторной разноуровневой доступности лесов - соответствующих ей режимов содержания и использования лесов (СИЛ), разработки для их поддержания различных моделей соответствующих типов приоритетно-целевых систем лесоводственных мероприятий.

Исходя из этой установки определена цель работы - разработать концептуальные основы определения, дифференциации и регулирования комплексной доступности лесов для установления доступно-целевых режимов их содержания и использования - путем применения соответствующих приоритетно-целевых лесоводственных систем, а также зонирования лесов по комплексной доступности, эффективного планирования, проектирования мероприятий лесоводства и лесопользования, разработки научно обоснованных программ развития лесного комплекса.

Для достижения цели сформированы и решены следующие задачи:

- дана оценка исторического опыта учета доступности участков леса для установления и поддержания целевого режима их содержания и использования;

- разработана концептуальная схема установления, регулирования и учета комплексной доступности лесов;

- сформирован алгоритм установления типов и видов режимов содержания и использования лесов и соответствующих им приоритетно-целевых систем лесоводственных мероприятий, выделяемых по целевому назначению и состоянию объектов лесоводства, с учетом их комплексной доступности;

- сформированы основные принципы зонирования лесов - объектов лесоводства по комплексной доступности для целей планирования, проектирования и рационального экономического обеспечения мероприятий содержания и использования лесов.

\section{Методы и материалы исследования}

Для решения поставленных задач использовался системный приоритетно-целевой метод лесоводства, обеспечивающий при его применении получение результатов всестороннего анализа состояния проблемы, условий ее возникновения, исторического изменения, применявшихся вариантов решений, выделения их недостатков, подлежащих устранению. В рамках реализации принятого метода, с учетом специфики решаемой проблемы, материалов литературных источников, а также имеющихся уже разработок в области определения содержания понятия доступности лесов и ее классификации [5], 
сформированы и использованы методологические подходы к разработке концептуальнометодических положений (концептуальной схемы) оценки комплексной доступности лесов с установлением дифференцированного режима их содержания и использования, обеспечиваемого разработкой и применением соответствующих приоритетно-целевых систем лесоводственных мероприятий определенных типов и видов, их моделей по интенсивности и целевому назначению, а также принципов зонирования лесов по КДЛ.

Решение комплекса намеченных задач и достижение цели работы обеспечивалось на основе материалов исследований по данной тематике, в том числе фондовых, а также содержащихся в литературных источниках, анализа положений нормативных и методических документов, регламентирующих применение и назначение лесоводственных мероприятий, а также материалов проектирования конкретных видов лесоводственных рубок ухода, рубок спелых перестойных насаждений для заготовки древесины (смены поколений леса), лесовосстановления и других мероприятий при лесоустройстве.

\section{Результаты и их обсуждение}

1. Оценка исторического опыта учета доступности участков леса для установления и поддержания целевого режима их содержания и использования

В процессе исторического развития наукой вырабатывались определенные показатели и критерии предельного воздействия на леса, в т. ч. эколого-лесоводственные требования к рубкам лесных насаждений, в целом к заготовке древесины (в объемах, по возрастам рубок и другим показателям), которые существенно определяют своеобразную «экологолесоводственную доступность лесов» для осуществления мероприятий лесопользования и связанного с ним лесовоспроизводства, содержания лесов [10, 11, 15, 16, 23].

В то же время различная доступность лесов всегда использовалась для определенного разделения - зонирования в целях обоснованного планирования рационального освоения лесов, развития лесной промышленности, организации и ведения лесного хозяйства, в т. ч. с выделением зон разной интенсивности лесопользования, преимущественно ресурсного - заготовки древесины, а затем и рекреационного [2, 24, 25].

В частности, в 70-80-х годах прошлого столетия в зависимости от природных и экономических условий обосновывалось выделение четырех зон по степени интенсивности (охвату участков лесов) рубок ухода: 1) интенсивных РУ; 2) умеренной интенсивности; 3) слабой и 4) очень слабой [25]. При этом, кроме уровня освоения расчетной лесосеки по главному пользованию, в качестве основных факторов, определяющих выделение указанных зон, учитывались фактически степень охвата рубками ухода транспортно доступных насаждений и уровень сбыта мелкой древесины - полный, неполный, ограниченный, а также полное отсутствие сбыта. В современных условиях существенное значение для определения уровня интенсивности лесопользования и ведения лесного хозяйства и выделения соответствующих территорий, районов интенсивного ведения лесного хозяйства имеет фактор собственно интенсивности рубок ухода $[2,26]$, что, безусловно, имеет определенное значение для ряда объектов лесоводства и лесопользования. Поскольку возможный целевой и допустимый уровень интенсивности рубок ухода зависит от многих свойств лесных экосистем и лесотипологических условий, устойчивости и целевого назначения лесов (эксплуатационных, защитных, в т. ч. их категорий), установление надежных интегрированных параметров показателей этих факторов является необходимым условием определения соответствующих видов и в целом - доступности лесов.

Естественная природная ограниченность увеличения интенсивности рубок ухода была установлена в результате широкомасштабных исследований еще в середине двадцатого сто- 
летия. Оценка влияния рубок ухода разной интенсивности на величину получаемого при разреживании т. н. дополнительного прироста, и за счет этого увеличение общего прироста и общей продуктивности древостоев позволила сделать вывод о невозможности достижения этой цели в более или менее существенных объемах и показателях - вероятно, не свыше 7-8 \% в идеальном варианте, а в реальной практике связано с рисками снижения общего прироста и утратой устойчивости сильно разреживаемых насаждений [4]. К тому же, достижение идеального варианта разреживания ограничено и технологической доступностью вырубаемых деревьев. В насаждениях естественного происхождения и лесных культурах при любой схеме их закладки и системе технологических коридоров, часть таких деревьев практически нельзя удалить из насаждения без повреждения или уничтожения сохраняемых деревьев. В то же время системное многократное проведение рубок ухода по циклу лесовоспроизводства, значительный совокупный объем получаемой при этом древесины и существенное улучшение качества выращиваемых древостоев - отражает в определенной мере общую интенсивность ведения лесного хозяйства, особенно в традиционных целях ресурсного, многоцелевого лесопользования [3, 4, 22].

Однако реализация такого режима рубок ухода и содержания лесов в целом возможна только в условиях высокой доступности участков для проведения лесоводственных мероприятий, причем не только транспортной, технической, экономической, но и своеобразной экологической. Для лесов многих категорий защитных лесов, особенно природоохранного назначения применение такого или подобного интенсивного режима СИЛ практически недоступно, так как может существенно изменить естественные свойства лесных экосистем. Не случайно высокоинтенсивные скандинавские технологии лесовыращивания получают нередко не только положительную, но и отрицательную оценку [13,
21]. «Лучшие лесопромышленные технологии (например, скандинавская технология), дают больший прирост древесины, но резко омолаживают лес и превращают его в парковые насаждения. Лес не достигает экологической зрелости, пустеет от многих видов биоты, деградирует как экосистема» [21, с. 232-233]. То же относится и к оценке плантационного или сходного с ним интенсивного выращивания высокопродуктивных хвойных древостоев на протяжении свыше двух столетий [14, 28], осторожное отрицательное отношение к которому сложилось еще у Г.Ф. Морозова в свое время [12].

В определенной мере в качестве важного фактора интенсификации и прогресса в лесном хозяйстве рассматривается переход к массовому созданию лесных культур на основе использования посадочного материала с закрытой корневой системой. Причем это поддерживается путем введения конкретных установок по наращиванию объемов в нормативный правовой документ - Правила лесовосстановления [18] и, соответственно, превращается в приоритетный фактор, ограничивающий доступность применения других видов мероприятий того же управляющего воздействия на объекты лесовосстановления, в т. ч. и менее затратных, и с возможно лучшим результатом в сложившихся региональных природно-хозяйственных условиях. Несмотря на имеющиеся определенные общие исходные преимущества этого варианта закладки лесных культур, результативность его в конкретных условиях и тем более сравнительная лесоводственная эколого-экономическая эффективность может быть оценена как минимум на стадии образования сомкнутых молодняков устойчивого целевого состава, а полная - по циклу лесовоспроизводства, в т. ч. с учетом потерь от ограничения экономической и экологической доступности выбора и проведения других (альтернативных) видов мероприятий.

В целом весь исторический опыт жесткого конкретного регламентирования применения определенных видов мероприятий (их мето- 
дов, нормативов), как правило, не приводил к положительному конечному результату в состоянии лесов. Для обеспечения такого результата необходимо устанавливать реально достижимые (доступные) цели режима содержания лесов, их проектируемые целевые параметры (характеристики), в т. ч. все промежуточные по стадиям цикла лесовоспроизводства, и предоставлять исполнителям возможность мотивированного выбора из существующих или создания новых наиболее эффективных видов и вариантов мероприятий, обеспечивая развитие техники лесоводства (в широком ее понятии).

\section{2. Концептуальная схема установления,} регулирования и учета комплексной доступности лесов

2.1. Исходные принципы определения комплексной доступности лесов и ее регулирования

В принципе, определение комплексной доступности лесов для установления режимов их содержания и использования, применения системных лесоводственных мероприятий разной интенсивности осуществляется дифференцированно по каждому типу и виду КДЛ, выделяемым по совокупности факторов и условий, влияющих в той или иной мере на возможность осуществления системных лесоводственных мероприятий на данной территории, с получением в результате общего, в том числе среднего и максимально ограниченного уровня (категории) доступности.

Для обеспечения системного установления интегрированной лесоводственной комплексной доступности лесов любого территориального объекта используется принципиальная схема, включающая последовательную взаимоувязанную оценку доступности по каждому и всем видам КДЛ, объединенным на высшем уровне ее классификации в три сложных таксона-комплекса, дифференцированные на типы, подтипы и виды доступности лесов (рис. 1).

При определении общей (интегрированной) КДЛ с использованием приведенной исходной схемы необходимо учитывать различную приоритетность факторов и, соответ- ственно, видов (типов, комплексов) доступности лесов, участков лесов, а также вероятность и возможность их изменения (обобщенно «возможную изменчивость»).

При том, что общая интегрированная комплексная доступность лесов как отдельных элементарных участков лесоводства - лесоводственного выдела (ЛВВд), в границах которого осуществляются системные лесоводственные мероприятия всего цикла лесовоспроизводства, в том числе включающего один или любое количество выделов, учитываемых при таксации лесов, так и сложных комплексных участков территориальных образований, принципиально определяется по всем факторным видам, типам и комплексам КДЛ (рис. 1). В то же время, учитывая огромное разнообразие лесов, региональных социальных, экологических и экономических условий, целесообразно использовать определенную вариантность последовательности рационального определения КДЛ, в том числе с учетом выделяемых специальных территориальных функциональных, целевых типов и видов комплексной доступности лесов, устанавливаемых для конкретных объектов лесоводства-лесопользования [5].

Регулирование комплексной доступности лесов элементарных и сложных территориальных объектов лесоводства-лесопользования осуществляется при необходимости в целях повышения доступности лесов, учитываемой при их освоении, планирования, проектирования и осуществления системных мероприятий содержания и использования лесов путем определения конкретных видов и типов КДЛ, ограничивающих общую доступность участка, с оценкой возможности, в том числе допустимости их изменений, а для комплексных участков территориальных образований - и целесообразности выделения (объединения) их в отдельные комплексные объекты (зоны), сходные по уровню доступности с установлением для них соответствующих типов режима содержания и использования, приоритетно-целевых систем лесоводственных мероприятий. 


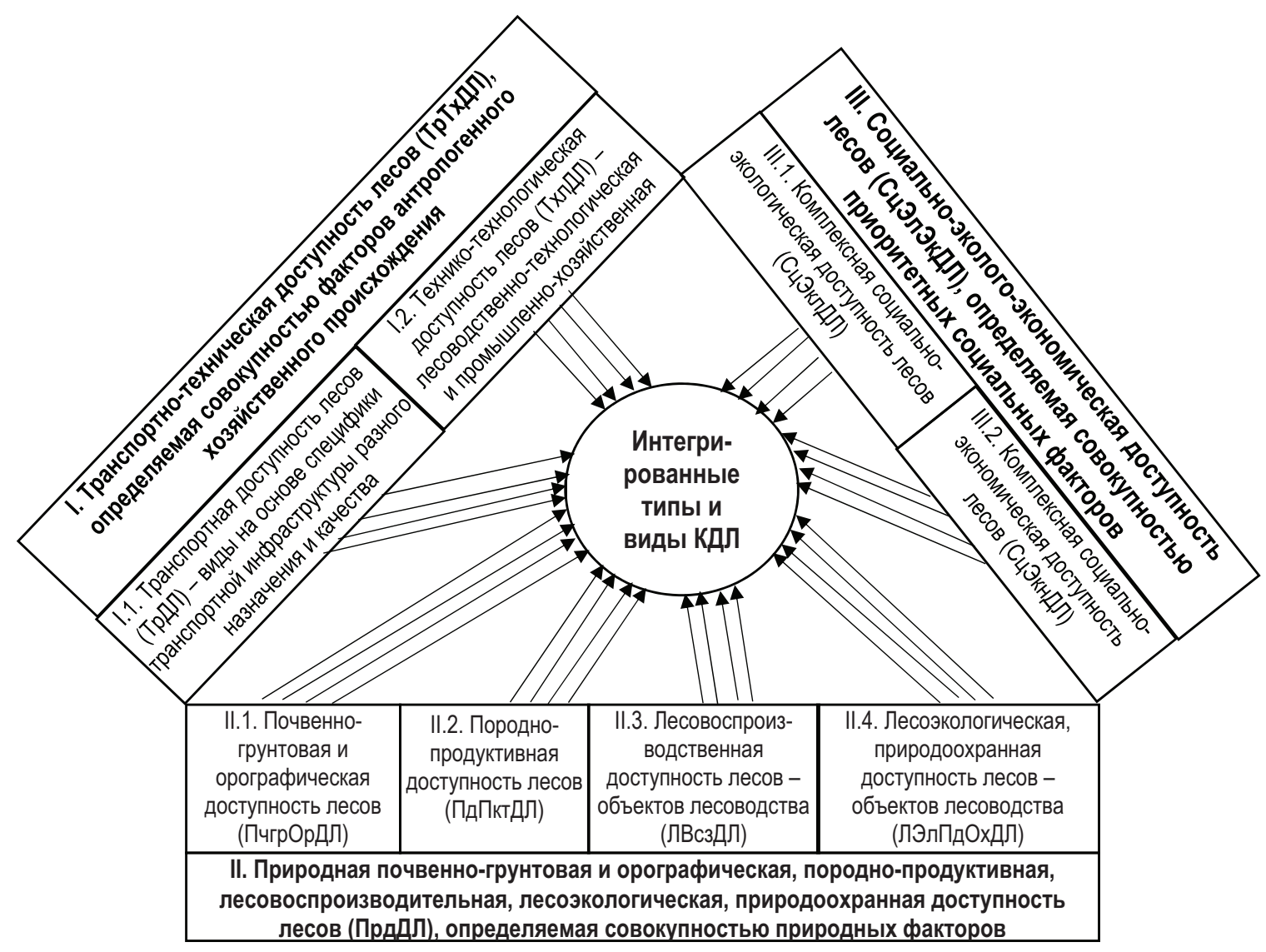

Рис. 1. Принципиальная схема установления интегрированной факторной комплексной доступности лесов (КДЛ) по ее типам и видам

2.2. Учет приоритетности видов комплексной доступности лесов

С учетом тенденций социального развития в стране и в мире в целом, возрастающей экологической ценности леса как важнейшего компонента окружающей природной среды, принципиально выделенные типы и, соответственно, виды доступности лесов, участков лесов (объектов лесоводства) по приоритетности рассмотрения и учета можно расположить в следующем порядке: от высшей природоохранной, экологической - поддержания лесов в состоянии непрерывного эффективного выполнения водоохранных, защитных, средообразующих и иных полезных функций, а следовательно, и социально-экологической, к высокой - природной лесовоспроизводи- тельной, почвенно-гидрологической и орографической, породно-продуктивной, а также традиционной умеренно-высокой транспортной, до умеренной технической и социальноэкономической (значение которой часто является определяющим при освоении лесов и осуществлении мероприятий лесоводства и лесопользования).

В то же время в зависимости от сложившихся условий и целей освоения лесов установленная на принципиальном уровне относительная приоритетность типов КДЛ может несколько меняться, а в пределах типов могут выделяться конкретные виды доступности лесов с более высоким приоритетом, в том числе и практически почти полностью блокирующие доступность лесов для выполнения 
мероприятий лесоводства и лесопользования. Это, в частности, относится к специфическим видам, включенным в комплексный тип лесоэкологической, природоохранной доступности лесов - объектов лесоводства (ЛЭлПдОхДЛ), выделяемым в связи с радиоактивным, техногенным загрязнением территории, другими нарушениями экологии, которые можно объединить в рамках динамичной (развиваемой) классификации КДЛ [5, 7] и в отдельный тип с несколькими подтипами для дифференцированного детального учета.

В свою очередь, при отсутствии для лесных участков значительных природоохранных, экологических и других ограничений доступности лесов первоприоритетными для учета будут другие типы и виды доступности объектов лесоводства. Следовательно, такое установление дифференциации типов и видов доступности лесов - конкретных элементарных объектов лесоводства на уровне лесоводственных выделов (ЛВВд) позволяет при других равных условиях выделять среди всех, имеющих для данного объекта существенное значение, - приоритетный вид, определяющий при сложившихся условиях по своему минимальному показателю уровень общей комплексной доступности лесов. В то же время при расчете общей комплексной доступности сложных (больших по площади) территориальных объектов по средневзвешенным показателям многих видов и типов КДЛ для всех составляющих таких объектов учет их приоритетности может осуществляться с использованием определенных «коэффициентов приоритетности».

\section{3. Учет возможной изменчивости видов} и типов комплексной доступности лесов

Важнейшее значение для разработки и реализации проектов развития лесных и других территорий, связанных с лесными, где освоение лесов является определенным компонентом в общей системе социально-эколого-экономического функционирования территориального образования, имеет установле- ние «возможнной изменчивости» доступности лесов по конкретным типам и видам, ограничивающим общую КДЛ, тем более с учетом затратности мероприятий на необходимые изменения, рисков нарушения экологической безопасности - утраты объектом значимых сущностных экологических, природоохранных свойств. Как правило, это связано и с лесоводственной безопасностью - предотвращением потери возобновительной способности, смены коренных пород на производные, упрощения пространственной и возрастной структуры - преобразования разновозрастных насаждений в одновозрастные, снижения биоразнообразия и устойчивости.

При всем разнообразии условий, влияющих на возможную (допустимую) изменчивость конкретных видов и типов доступности лесов, на принципиальном методологическом уровне - с учетом не только пожарной, санитарной, но и более общей лесоводственной (в широком понимании), а также экологической, в первую очередь, природоохранной, и соответственно, социально-экологической безопасности, выделенные типы и объединяемые ими виды доступности лесов можно относительно разделить в целях дифференцированного учета по степени допустимой изменчивости на несколько (три-пять) категорий возможной изменчивости - от высшей и высокой до умеренной, низкой и очень низкой или нулевой.

Высокая изменчивость доступности отражает, как правило, возможность практически неограниченного изменения уровня (категории) доступности - до высшей (пятой). Такая изменчивость может быть установлена для технической доступности лесов, поскольку оснащенность техническими средствами, при неограниченном их совершенствовании, может обеспечивать выполнение всех лесоводственных мероприятий, а также и производство по переработке древесины и других лесных ресурсов.

Относительно высокая изменчивость может быть установлена для транспортной доступности лесов, также при условии неогра- 
ниченного совершенствования создаваемой транспортной инфраструктуры, в т. ч. органично включаемой в природные ландшафты, исключая существенные нарушения их, происходящих в них процессов, чего, тем не менее, полностью избежать, скорее всего, невозможно.

Умеренно-ограниченной (и даже относительно высокой для конкретных объектов) изменчивостью можно характеризовать, вероятно, породно-продуктивную доступность лесов, особенно с учетом того, что эти показатели существующих лесов значительно ниже потенциально обеспечиваемых лесорастительными условиями при выращивании древостоев целевых, преимущественно коренных пород, без изменения в то же время других видов природной доступности лесов.

В высокой степени консервативными (малоизменяемыми) следует признать в основном все другие виды природной доступности лесов (при установке на сохранение природных естественных свойств лесных экосистем), относящиеся к типам почвенно-грунтовой, орографической, а также лесовоспроизводительной доступности лесов, вероятно, за исключением отдельных участков разной величины, где допустимо научно обоснованное экологической и лесоводственной безопасностью изменение лесорастительных условий мелиорацией (осушением, обводнением), тем более, по существу, при восстановлении нарушенных в прошлом гео- и экосистем.

Как правило, практически неизменяемой является природоохранная доступность лесов - если она установлена вполне обоснованно, с выделением действительно уникальных лесных и комплексных с лесными экосистем, тем более подлежащих сохранению без вмешательства человека, а также и объектов менее строгой охраны, которые нельзя сохранить при активном типичном освоении лесов, в т. ч. в социально-экологических целях рекреации, туризма и других.

Виды социально-экологической доступности лесов, в зависимости от специфики объектов лесоводства, для которых они устанавливаются, могут быть практически неизменяемыми, если участки имеют особое природоохранное значение (по существу, виды социально-природоохранной доступности), а также малоизменяемыми и относительно (умеренно) изменяемыми - для сравнительно больших участков лесов, имеющих преимущественно средообразующее, защитное, санитарно-гигиеническое значение и относящихся к категориям защитных лесов - леса, расположенные в лесостепной зоне, леса зеленых зон вокруг населенных пунктов и другие.

Социально-экономическая доступность лесов в зависимости от многих условий может отличаться как высокой изменчивостью при наличии надежных источников средств для развития территорий, так и существенно ограниченной - при отсутствии таких источников, в т.ч. внутренних - потенциала продуктивных лесов, которые можно осваивать и в экономических целях (эффективная заготовка древесины и др.).

Умеренной и даже сравнительно высокой изменчивостью характеризуются и многие другие факторные типы и виды социальноэколого-экономического комплекса доступности лесов. Существенные изменения их (и, соответственно, определяемых в значительной мере социальными - технических, транспортных и других видов доступности лесов - объектов лесоводства и лесопользования) могут происходить в связи с усилением общественного движения за сохранение лесов, в том числе малонарушенных, высокой природоохранной ценности, объектов национального лесного наследия [1, 8, 27], а также принятием на федеральном, региональном уровнях решений органами управления по освоению и развитию территорий.

2.4. Последовательность установления общего уровня комплексной доступности лесов

Последовательность определения отдельных видов доступности лесов и образуемых ими комплексных и более простых типов не 
имеет принципиального значения, но обоснованный выбор ее может существенно сократить сроки, затраты времени и средств на получение результата.

Учитывая специфику выделяемых видов и объединяющих их типов КДЛ, для установления общего уровня комплексной доступности элементарных и сложных территориальных объектов лесоводства-лесопользования, в первую очередь, целесообразно определять показатели уровня доступности по практически неизменяемым и мало изменяемым видам КДЛ, определяемым природными естественными свойствами самосохранения хрупких лесных и комплексных с лесными экосистем, почвенно-грунтовыми и орографическими условиями, породно-продуктивным и лесовоспроизводительным потенциалом, а также связанных с сильными нарушениями окружающей природной среды территорий (в результате радиоактивного, техногенного загрязнений и других негативных процессов). Затем при получении показателей приемлемого уровня доступности по этим видам КДЛ осуществляется определение фактических параметров показателей транспортной и технической доступности (изменение которых возможно путем хозяйственной деятельности строительства дорог, промышленных предприятий по переработке древесины и т. п.). С использованием полученных данных, а также с учетом социальных потребностей в лесах и лесных ресурсах, наличия средств на необходимое развитие транспортной, технической, социальной инфраструктуры на завершающем этапе определяются социально-экологическая и социально-экономическая, а на их основе - общая комплексная лесоводственная доступность лесов.

Следовательно, в наиболее распространенных типичных условиях оценку комплексной доступности лесов (преимущественно эксплуатационных) для многоцелевого и приоритетно-моноцелевого интенсивного использования и воспроизводства, получения лесных древесных ресурсов целесообразно на- чинать по показателям экологической, природоохранной и социально-экологической доступности, которыми может существенно ограничиваться общая комплексная доступность лесов, в т. Ч. в совокупности с породнопродуктивной и лесовоспроизводительной, определяемыми показателями продуктивности и естественной воспроизводительности лесов, а также другими составляющими КДЛ, относящимися к практически неизменяемым, в т. ч. мало- или «высокозатратноизменяемым» (базирующимися на почвенно-лесотипологических условиях, биологических свойствах лесообразующих пород, слабой природной устойчивости гео- и экосистем, их природоохранной значимости и т. п.), тем более, что предварительные данные по этим показателям лесов уже имеются в лесоустроительных и других материалах учета лесов.

При известном или установленном на предварительном этапе отсутствии особых экологических, природоохранных ограничений многоцелевого лесопользования-лесовоспроизводства, в том числе при обоснованном выделении специальных типов и видов КДЛ [5] - для определенных видов целевого назначения лесов и/или комплексных участков определенных видов лесопользования (полученных/предоставленных в аренду для заготовки древесины и других видов использования лесов) возможна первичная оценка доступности лесов и по традиционным показателям транспортно-технической, технологической, а возможно, и своеобразной «промышленно-хозяйственной» доступности в сочетании с природной породно-продуктивной. Они определяются, соответственно, наличием и развитием транспортной инфраструктуры и промышленности по переработке древесины, а также хозяйства по ее использованию (на строительство и др. цели), что в целом отражает и потребность в лесных ресурсах, и, следовательно, экономическую и комплексную лесоводственную доступность - соответственно, при наличии ресурсного потенциала лесов. 
2.5. Алгоритм регулирования и учета доступности лесов элементарных и комплексных объектов лесоводства-лесопользования

При необходимости регулирования, изменения - обычно увеличения - существующей комплексной доступности лесов элементарного объекта лесоводства на уровне лесоводственного выдела (ЛВВд), т. е. повышения сложившегося уровня его доступности, определяемого фактически по минимальному значению категории конкретного вида и типа КДЛ, имеющего высший среди других приоритет, осуществляется оценка изменчивости данного вида КДЛ - возможности перевода его на более высокий уровень с учетом затратности проведения необходимых для достижения цели мероприятий и, соответственно, экономической (социально-экономической) доступности их осуществления.

В случае установления возможности реализации этой регулирующей операции, если расчетное или реальное увеличение (повышение уровня) комплексной доступности лесов окажется недостаточным, ограниченным минимальным показателем категории доступности того же или следующего приоритетного (среди других) вида КДЛ, осуществляется следующий шаг (этап) оценки изменчивости этого или иного вида доступности объекта лесоводства и возможности ее увеличения за счет проведения необходимых для этого мероприятий.

Соответственно, такое поэтапное рассмотрение и оценка возможности изменения увеличения минимальной доступности лесов очередных по приоритетности видов КДЛ продолжаются до достижения приемлемого уровня комплексной доступности лесов объекта или установления невозможности последующего изменения (повышения) доступности в связи с недостатками средств для осуществления мероприятий по изменению факторов (условий), ограничивающих доступность, или с очень низкой результативностью их расходования, а также невозможностью при наличии любых средств и социально-экономических установок улучшить доступность лесов по дан- ному практически неизменяемому виду доступности (природоохранному или иному).

Для комплексных объектов лесоводства, состоящих из нескольких или множества элементарных, лесов территориальных образований различной величины, в том числе при зонировании территории по комплексной доступности, для планирования, проектирования мероприятий лесоводства и лесопользования, а также для экономического обеспечения их выполнения необходимо определение общих средних показателей комплексной доступности по всей совокупности объединяемых участков, в том числе по факторным комплексам, типам и, возможно, ключевым видам доступности, определяющим уровень КДЛ в целом. В частности, при отсутствии транспортной инфраструктуры на больших территориях и невозможности ее создания в приемлемый период времени - то есть при практически полной транспортной недоступности лесов нет необходимости рассчитывать доступность по другим видам КДЛ по всем или каждому элементарному объекту лесоводства-лесопользования. В то же время для комплексных объектов, включающих участки с разной доступностью по видам и типам для тех же целей целесообразно рассчитывать показатели доступности - средневзвешенные по площади участков, а для принятия решений по освоению лесов в целях заготовки древесины или других ресурсов - и через их запасы. При этом для учета специфики каждого элементарного объекта лесоводства необходимо установление сложившегося уровня его доступности по приоритетным видам КДЛ с оценкой реальной возможности изменения (повышения) доступности участка для осуществления эффективных лесоводственных мероприятий содержания лесов и лесопользования.

Учитывая, что для многих объектов лесоводства-лесопользования, в том числе эксплуатационных лесов, передаваемых в аренду для заготовки древесины и других ресурсов, показатели уровня устанавливаемых традиционных видов доступности лесов - транспорт- 
ной, технической, технологической и других вполне могут быть изменены при наличии средств и социально-экономической потребности в развитии территории; рассмотрение их в сочетании с показателями установленной (или известной по имеющимся лесоустроительным и другим данным) природной доступности лесов (породно-продуктивной, лесовоспроизводительной), вполне обеспечивает возможность определения общей лесоводственной комплексной доступности лесов для многоцелевого их освоения и использования.

В целом при любом варианте определения доступности лесов по всем или выделенным специальным определяющим видам и типам комплексной доступности лесов, общая оценка уровня доступности при других равных условиях для элементарных объектов лесоводства принимается равной низшему показателю уровня доступности конкретных видов КДЛ. При этом, если показатели других видов доступности существенно выше или могут быть такими под управляющим воздействием соответствующих мероприятий, дается оценка возможности изменения выделяющихся критических видов или отдельного вида доступности (при условии, что они относятся к изменяемым). В положительном варианте оценки принимается решение о проведении мероприятий по улучшению условий осуществления целевого содержания и использования лесов рассматриваемого объекта лесоводства-лесопользования путем повышения его доступности для применения более эффективных лесоводственных систем СИЛ, в частности, к таким мерам существенного изменения условий доступности лесов может относиться строительство участков дорог, приобретение необходимых технических средств и развитие технологий реализации лесоводственных мероприятий, а также осуществление предварительного содействия естественному лесовозобновлению и исключение необходимости назначения, проектирования практически недоступных, но традиционно планируемых мероприятий создания лесных культур (при невозможности системного осуществления ухода за ними).
С использованием представленного алгоритма принципиальных действий по определению комплексной доступности лесов, ее уровня по выделенным типам и видам, с учетом их приоритетности и изменчивости, могут разрабатываться математические модели оперативного расчета возможных изменений и осуществления регулирования КДЛ. Это обеспечит возможность сравнения и выбора наиболее приемлемых вариантов изменения (увеличения) комплексной доступности лесов с определением необходимых для этого затрат на их осуществление и оценки эффективности, целесообразности проведения соответствующих операций.

3. Установление типов и видов режсмов содержания и использования лесов и соответствующих им приоритетно-целевых систем лесоводственных мероприятий, выделяемых по целевому назначению и состоянию объектов лесоводства с учетом их комплексной доступности

В результате осуществления - в соответствии с приведенной концептуальной схемой - оценки доступности лесов, участков лесов по каждому факторному типу и виду, на основе полученных данных, с учетом определенной их приоритетности и изменчивости, устанавливаются общие интегрированные оценки комплексной доступности любого участка - объекта лесоводства по категориям КДЛ. Исходя из этого, для каждого участка можно выбирать (согласно установленной доступности) с использованием интенсивно развивающихся методов и технологий математического моделирования наиболее востребуемые, действительно практически реализуемые режимы СИЛ (лесопользования и содержания лесов) и приводить им в соответствие (формировать из имеющихся, разрабатывать новые для поддержания установленного режима) доступные для осуществления сравнительно наиболее эффективные системы лесоводственных мероприятий по интенсивности с учетом целевого назначения лесов (рис. 2). 


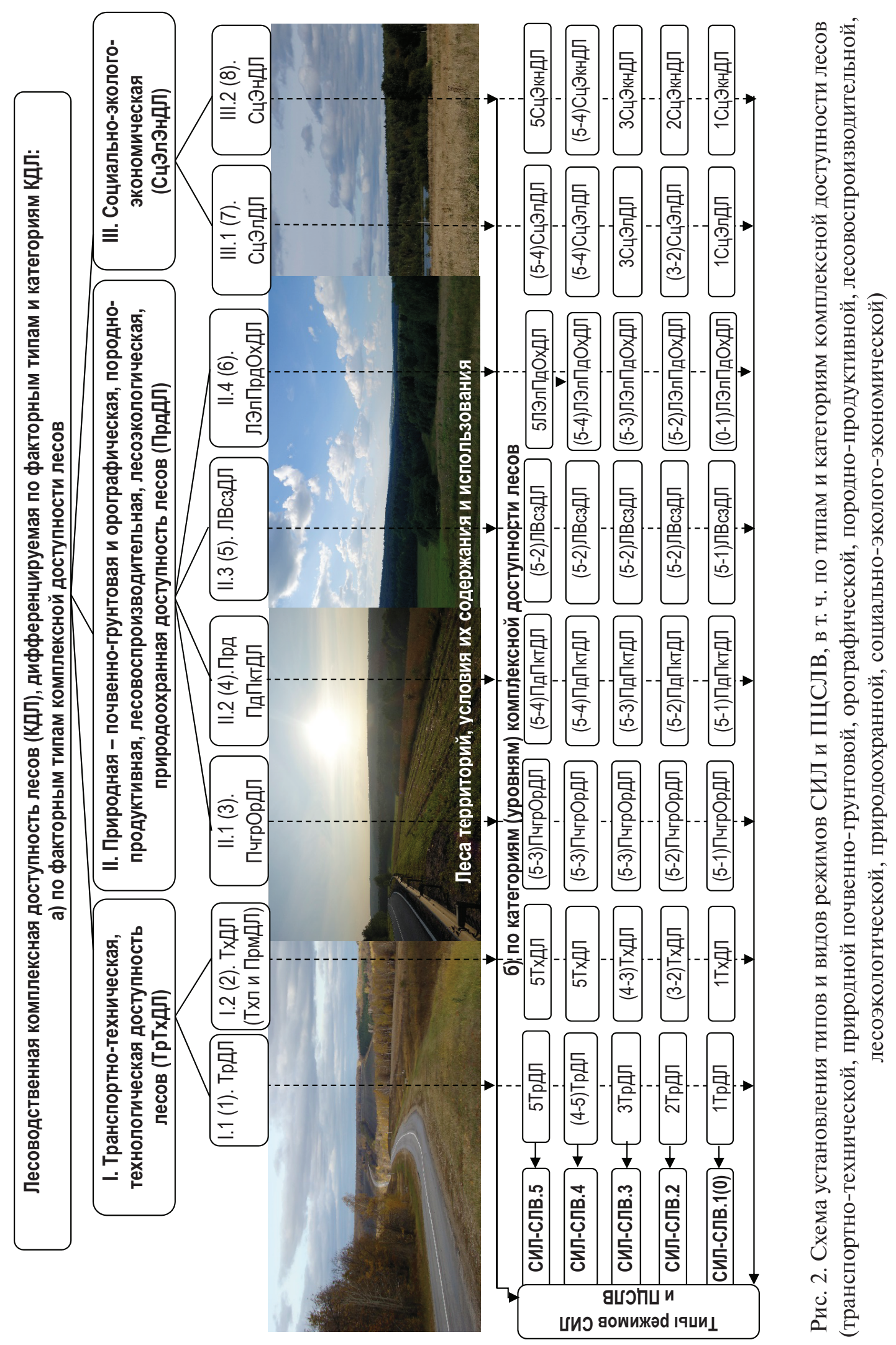


Поскольку леса практически почти любого территориального образования представляют собой сложные территориальные комплексы зонально-ландшафтно-типологических участков разного целевого назначения, они объединяются по сходству и различию в определенные типы и виды природно-целевых объектов лесоводства с дифференциацией их по уровням (категориям) комплексной доступности и установлением по каждой такой категории соответствующего режима содержания и использования лесов и обеспечивающих его поддержание приоритетно-целевых систем лесоводственных мероприятий - определенных типов и видов по интенсивности и целевому назначению.
Соответственно установленным типам режимов содержания лесов и лесопользования предусматривается относительное распределение по ним применяемых или возможных для применения типов приоритетноцелевых систем лесоводственных мероприятий, дифференцируемых по интенсивности и целевому назначению, в том числе эксплуатационно-восстановительного, восстановительно-эксплуатационного (лесовосстановительного), эколого-природоохранного обновительного типа целевого назначения лесов, определенной общей интенсивности воздействия на объекты лесоводства - от очень высокой до умеренной и очень низкой (рис. 3).

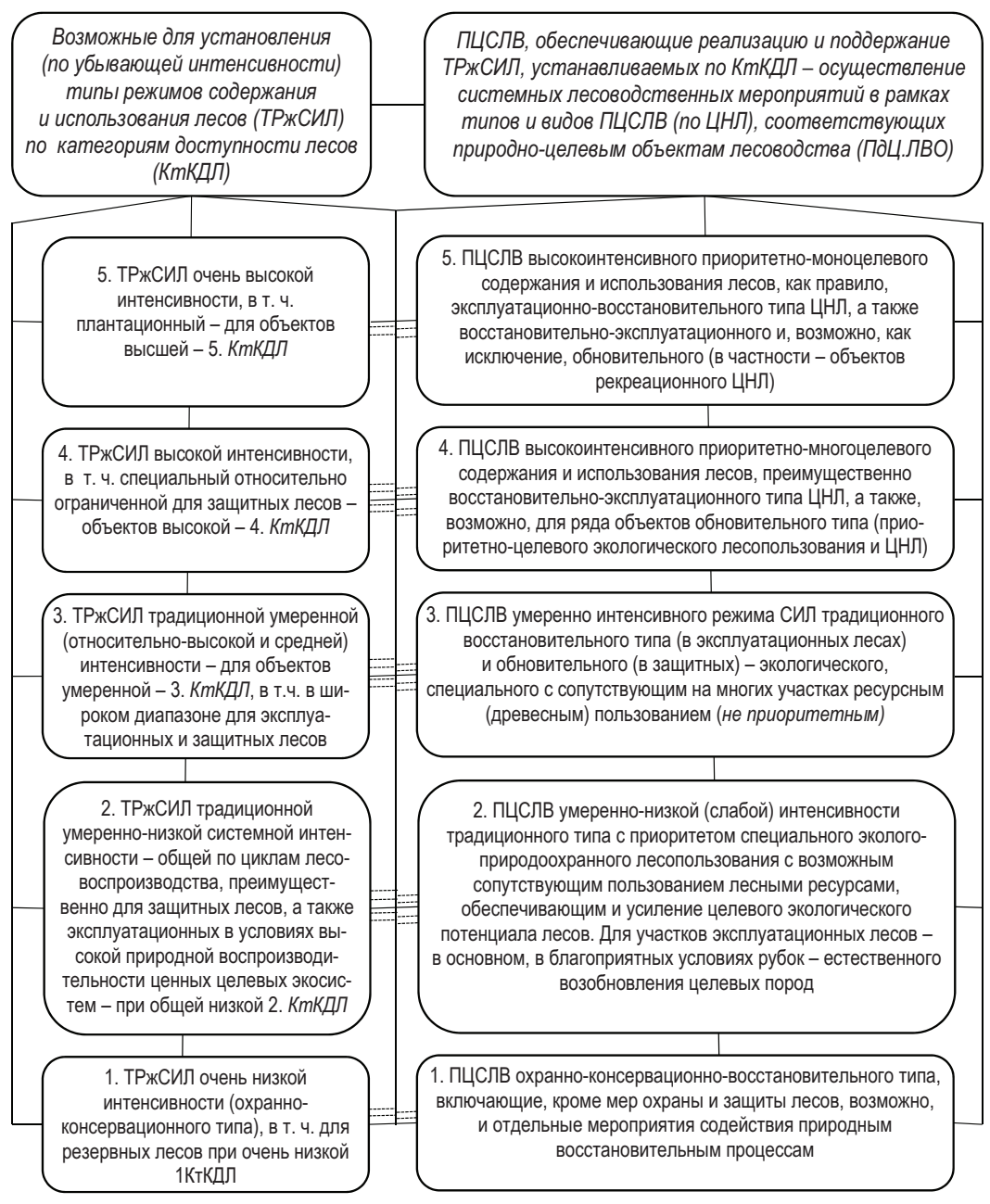

Рис. 3. Относительное распределение применяемых или возможных для применения типов приоритетно-целевых систем лесоводственных мероприятий по типам режимов содержания и использования лесов, устанавливаемых с учетом категорий их доступности 
Учитывая, что в реальных условиях ведения лесного хозяйства, лесопользования, управления лесами режим содержания лесов, а также и состав обеспечивающих его поддержание систем лесоводственных мероприятий дифференцируются соответственно таксонам лесоводственной классификации лесов по целевому назначению (типам и видам ЦНЛ), а также - по классификационным единицам состояния объектов лесоводства - отличия существующего от целевого, обеспечиваемого лесотипологическими (лесорастительными) условиями и биологическими свойствами лесообразующих пород, с учетом классификации доступности лесов, всех объектов лесоводства - разделения их на пять категорий по уровню доступности; фактически реализуемые «доступно-целевые интегрированные типы и виды режима СИЛ и соответствующие им ПЦСЛВ» (ДЦ.РжСИЛ и ДЦ.ПЦСЛВ) необходимо устанавливать по трем определяющим классификационным признакам: целевое назначение лесов, состояние лесов, доступность лесов.

Соответственно, виды ДЦ.РжСИЛ и ДЦ.ПЦСЛВ в конкретных условиях устанавливаются путем выбора из возможных в разной мере целевых вариантов СИЛ и ПЦСЛВ, выделяемых по целевому назначению и состоянию лесов - надежно практически реализуемых при установленном уровне доступности лесов (рис. 4).

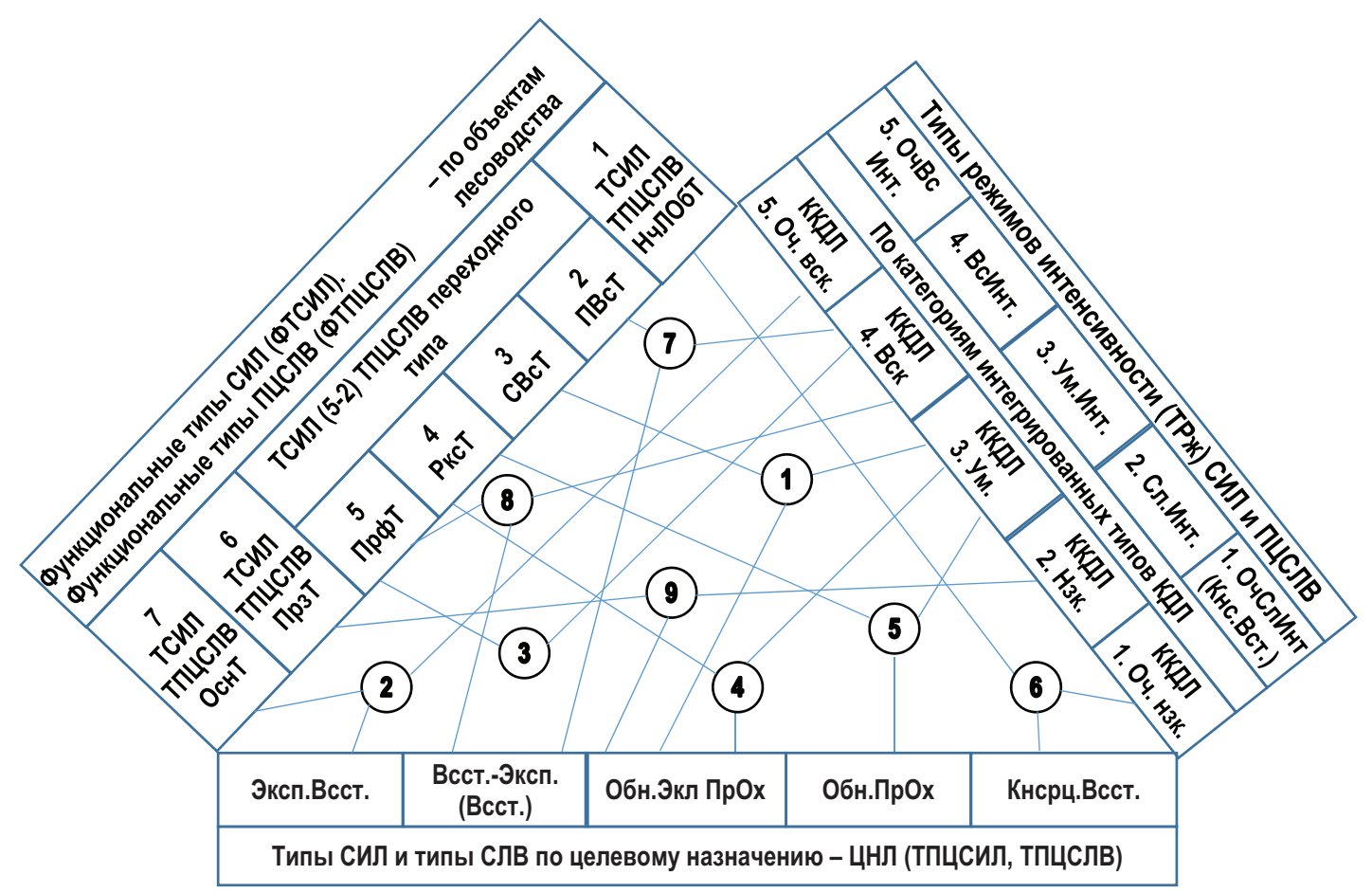

Рис. 4. Схема установления (выбора) типов и видов СИЛ и ПЦСЛВ, выделяемых по целевому назначению и состоянию лесов, реально (доступно) реализуемых при установленном уровне (категории) комплексной доступности лесов

Типы и виды ПЦСЛВ по функциональным типам доступно целевых режимов СИЛ (ДЦРжСИЛ) по интенсивности, интегрированным типам и категориям комплексной доступности лесов (ККДЛ) - примеры:
1. ПЦСЛВ:ОбнЭклПрОх.СВст.УмИнтУмКДЛ - ПЦСЛВ обновительно-экологоприродоохранного ЦНЛ санитарно-восстановительного функционального типа умеренной интенсивности режима СИЛ, при относи- 
тельно ограниченной (умеренной) комплексной доступности лесов.

2. ПЦСЛВ:ЭкспВсст.Осн.ОчВсИнтОчВсКДЛ - ПЦСЛВ эксплуатационно-восстановительного типа ЦНЛ основного функционального типа моно-приоритетного очень высокой интенсивности режима СИЛ, при очень высокой комплексной доступности лесов.

3. ПЦСЛВ:ВсстЭксп.Прф.ВсИнтВсКДЛ - ПЦСЛВ восстановительно-эксплуатационного ЦНЛ переформировательного функционального типа высокоинтенсивного многоцелевого режима СИЛ, при очень высокой КДЛ.

4. ПЦСЛВ:ОбнЭклПрОх.Ркс.УмИнтУмКДЛ - ПЦСЛВ эколого-обновительного природоохранного ЦНЛ реконструктивного функционального типа умеренной интенсивности режима СИЛ, при относительно ограниченной - умеренной доступности лесов.

5. ПЦСЛВ:Обн ПрОх.Ркс.УмИнтУмКДЛ - ПЦСЛВ обновительно-природоохранного типа ЦНЛ реконструктивного функционального типа умеренной интенсивности режима СИЛ, при относительно ограниченной - умеренной комплексной доступности лесов.

6. ПЦСЛВ:КнсрцВсст.НчЛОб.ОчСлИнтОчНзкКДЛ - ПЦСЛВ консервационно-восстановительного ЦНЛ начально-лесообразовательного функционального типа (лесораспространения) очень слабой интенсивности режима СИЛ, при очень низкой доступности объектов лесоводства.

7. ПЦСЛВ:ВсстЭксп.ПВст. ВсИнтВсКДЛ - ПЦСЛВ восстановительно-эксплуатационного типа ЦНЛ первично-восстановительного функционального типа высокой интенсивности многоцелевого режима СИЛ, при высокой КДЛ (в т. ч. для насаждений плантационного типа, но многоцелевого назначения).

8. ПЦСЛВ:ВсстЭксп.Прф.ВсИнтВсКДЛ - ПЦСЛВ восстановительно-эксплуатационного типа ЦНЛ переформировательного функционального типа высокой интенсивности режима СИЛ, при высокой КДЛ (в т. ч. для лиственно-хвойных насаждений, переформируемых в насаждения плантационного типа лесовыращивания).

9. ПЦСЛВ:ОбнЭклПрОх.Прз.СлИнтНзкКДЛ - ПЦСЛВ обновительно-экологоприродоохранного типа ЦНЛ производного функционального типа слабоинтенсивного режима СИЛ в условиях низкой КДЛ (в т. ч. для производных временно целевых березняков вегетативного происхождения, выращиваемых при низкой эколого-экономической доступности для преобразования в целевые насаждения основного типа).

4. Основные принципы зонирования лесов объектов лесоводства по комплексной доступности для целей планирования, проектирования и рационального экономического обеспечения мероприятий по содержанию и использованию лесов

Принципиально, зонирование лесов по лесоводственной комплексной доступности осуществляется на основе установления разных уровней доступности лесных участков определенной, более или менее большой территории - страны, региона, субъекта РФ, района, хозяйственной территориальной единицы управления лесами, ведения лесного хозяйства, в т. ч. лесных участков, передаваемых (получаемых) в пользование.

При этом, учитывая, что в пределах многих выделяемых в разных целях территорий, даже не слишком больших по площади, окажутся, как правило, участки разного уровня комплексной доступности, установление зон определенной категории доступности осуществляется по совокупности показателей и критериев, включая: преобладающий уровень доступности большинства составляющих участков - по совокупной их площади, с учетом возможного приоритета целевого назначения лесов, а также связанных с ним видов доступности; минимальной площади выделяемой зоны в абсолютных или относительных параметрах; целевых установок перспек- 
тивного развития территорий и потребностей социума в лесах и/или лесных ресурсах.

На каждом последующем территориальном образовании более высокого (по величине площади) ранга выделяемые по преобладающему, средневзвешенному или приоритетному (в том числе с учетом перспектив развития) уровню доступности лесов зоны неизбежно будут включать первичные (простые), а затем и комплексные участки лесов разных категорий доступности и, соответственно, режимов содержания и использования лесов без замены их на преобладающий или принятый общий (основной) для этой зоны.

Следовательно, при практически любой нормативно установленной минимальной площади зоны комплексной доступности лесов на территории высокой общности (страны, региона, района и т. п.) при каждом последующем переходе на более низкий уровень устанавливается, соответственно, более детальное (дробное) зонирование с выделением комплексных или даже отдельных участков одной категории доступности.

Границы между территориями, участками лесов разной комплексной доступности устанавливаются по общему интегрированному показателю комплексной доступности лесов, определенному в рамках сформированного концептуального подхода - на основе учета по конкретным методикам, программам всех составляющих показателей КДЛ. При этом за исходную-первичную территориальную единицу принимается выделэлементарный или комплексный лесоводственный (ЛВВд) - участок леса - однородный в своих границах по совокупности принятых показателей, базирующихся на постоянстве границ однородных лесорастительных условий и единого целевого назначения лесов - объект применения мероприятий определенных лесоводственных систем, в т. ч. с относительно равномерным и территориально дискретно-выборочным воздействием на участки многоприемных, любой продолжительности периода повторения приемов (чересполосных, площадковых, куртинных, котловинных рубок и других), по всему циклу лесовоспроизводства или существования одного или нескольких поколений леса или последовательно сменяющихся одновозрастных лесных насаждений. Это не зависит от количества включенных в природно-целевой объект лесоводства элементарных таксационных выделов или их частей, объединенных в ЛВВд, представляющий участок применения одного вида ПЦСЛВ или одного комплекса взаимосвязанных лесоводственных функциональных систем (основного, производного, переходного, начальнолесообразовательного типов), выделяемых по целевому назначению, отличию существующих участков от целевых и интенсивности для поддержания соответствующего режима СИЛ, устанавливаемого по комплексной доступности лесов.

Комплексный лесоводственный выдел определенного режима содержания и использования лесов - одного комплекса систем ПЦСЛВ сохраняется в своих границах, как правило, более или менее относительно постоянно и даже при появлении возможности смены режима СИЛ и ПЦСЛВ на всей его площади с последовательным проектированием и осуществлением очередных приемов и видов системных мероприятий, в т. ч. на отдельных его частях (соответствующих по своим характеристикам различным элементарным таксационным выделам) - в частности, на участках дискретно-выборочных рубок с двух-четырех-приемной закладкой лесных культур.

При изменении уровня (категории) комплексной доступности участка лесоводственного выдела он включается, соответственно, в другую зону КДЛ. С учетом целевых установок содержания и использования лесов всего участка или его части при повышении доступности - категории КДЛ (с улучшением транспортной инфраструктуры и других условий осуществления мероприятий) - интенсивность 
режима СИЛ и применяемой ПЦСЛВ может сохраняться до завершения определенного этапа, а также полного цикла ЛВП или увеличиваться в рамках соответствующего типа целевого назначения систем лесоводственных мероприятий. При снижении уровня комплексной доступности участка и включении его в соответствующую зону КДЛ (в связи с усилением экологических, природоохранных требований - переводом в защитные леса определенной категории с ограниченной доступностью) режим СИЛ по интенсивности меняется с введением в ПЦСЛВ необходимых коррективов, обеспечивающих более или менее плавный переход к целевому типу лесоводственных систем без отрицательных для состояния участка последствий. При снижении уровня (категории) комплексной доступности части участка лесоводственного выдела и интенсивности режима СИЛ и типа ПЦСЛВ она в своих границах выделяется в отдельный участок - ЛВВд и переводится в соответствующую зону КДЛ.

Такое системное зонирование лесов по комплексной доступности может использоваться для разного уровня планирования ведения лесного хозяйства и осуществления лесопользования, развития территорий, а также распределения средств на содержание и использование лесов - при установленном среднем уровне доступности лесов (с различием не менее чем на единицу) и определением в то же время доли площади участков каждой категории доступности, объединенных в границах зоны.

Следовательно, в границах любой (в т. ч. минимальной) по площади зоны с принятым средним или иным общим уровнем доступности реальный режим содержания и использования лесов должен устанавливаться непосредственно для каждого участка по уровню его доступности.

\section{Заключение}

На основе использования выделенных подсистем показателей факторов, влияющих на доступность лесов, и соответствующих им её видов сформирована концептуальная схема установления комплексной доступности лесов для каждого элементарного участка - природно-целевого объекта лесоводства и лесопользования и, соответственно, - объединяющих их комплексных участков и лесов территориальных образований.

При этом, согласно разработанной схеме в сложившихся природных, хозяйственнотранспортно-технических и социально-эколого-экономических условиях, с определением перспектив преобразования и развития отдельных их составляющих, отражаемых в соответствующих видах и типах комплексной доступности лесов, с учетом их приоритетности и возможной изменчивости, осуществляется установление, реально обеспечиваемого проведением системных лесоводственных мероприятий (ПЦСЛВ), доступно-целевого режима содержания и использования лесов (СИЛ), путем взаимосогласованного сочетания наиболее эффективных в этих условиях типов, видов и вариантов СИЛ и ПЦСЛв. Они устанавливаются по трем системообразующим признакам, в т. ч. - целевого назначения и конкретных целей содержания и использования лесов - объектов лесоводства, отличия фактического их состояния от целевого, обеспечиваемого природным лесотипологическим потенциалом, включая биологические свойства лесообразующих пород, а также возможных режимов интенсивности, соответствующих уровням (категориям) доступности лесов.

В свою очередь, зонирование лесов по комплексной доступности в пределах любой территории осуществляется на основе совокупной оценки, определяемой на основе учета категорий доступности, установленных по каждому элементарному участку или комплексным участкам, выделяемым при достигнутом современном уровне развития методов и точности определения параметров принятых показателей и критериев, характеризующих выделяемые объекты лесоводства и лесоустройства, дифференциацию их на состав- 
ляющие до отдельных элементарных выделов, для которых проектируются все системные лесоводственные мероприятия по циклам лесовоспроизводства.

В качестве отдельных зон выделяются части территории с одинаковым или сходным уровнем доступности (по показателям - средневзвешенным по площади) составляющих ее участков, отличающихся от других не менее чем на единицу по принятой пятибалльной шкале категорий комплексной доступности лесов (от высшей до умеренной и почти пол- ной недоступности). При этом для территории каждой выделенной зоны устанавливается соотношение площадей участков (в т. ч. процентное) всех включенных в нее разных категорий доступности, определяющих реальные возможности установления конкретного доступно-целевого режима интенсивности содержания и использования лесов и обеспечивающих его поддержание социально-экономически доступных для применения приоритетно-целевых систем лесоводственных мероприятий.

\section{БИБЛИОГРАФИЧЕСКИЙ СПИСОК}

1. Аксенов, Д. Концептуальные подходы к созданию национального лесного наследия Российской Федерации / Д. Аксенов, К. Кобяков, Н. Шматков, А. Ярошенко // Устойчивое лесопользование. - 2015. № 3 (43). - С. 2-8.

2. Актуальные вопросы интенсификации лесопользования в России. Интервью с Б. Романюком, научным руководителем проекта «Псковский модельный лес» и фонда «Грин Форест» // Устойчивое лесопользование. - 2011. - № 4 (29). - С. 2-6.

3. Атрохин, В.Г. Формирование высокопродуктивных насаждений / В.Г. Атрохин. - М.: Лесн. пром-сть, 1980. -232 c.

4. Георгиевский, Н.П. Рубки ухода за лесом / Н.П. Георгиевский. - М.: Гослесбумиздат, 1957. - 142 с.

5. Желдак, В.И. Концептуальные вопросы определения содержания и систематизации лесоводственной комплексной доступности лесов / В.И. Желдак. // Тр. Санкт-Петербургского НИИ лесного хоз-ва. СПб.: СПбНИИЛХ, 2021. - № 1. - С. 31-54.

6. Желдак, В.И. Системы лесоводственных мероприятий для моделей разного режима содержания лесов и лесопользования / В.И. Желдак // Лесотехнический журнал. - 2017. - Т. 8. - № 4 (28). - С. 55-71.

7. Желдак, В.И. Систематизация и учет факторов и условий доступности лесов для осуществления лесоводственных мероприятий / В.И. Желдак, Э.В. Дорощенкова, Е.М. Сидоренкова, Т.В. Липкина, И.Ю. Прока // Лесохозяйственная информация. - 2021. - № 1. - C. 18-39. DOI 10.24419/LHI.23043083.2021.1.02

8. Ильина, О. Потенциальные объекты национального лесного наследия севера европейской части России / О. Ильина, А. Марковский, Е. Пилипенко, А. Родионов // Устойчивое управление. - 2016. - № 3 (47). - С. 8-15.

9. Лесной кодекс Российской Федерации [Электронный ресурс]: от 04.12.2006 № 200-Ф3 (ред. от 30.04.2021). URL: http://www.consultant.ru/

10. Лесоводственные требования к технологическим процессам лесосечных работ. - М.: ВНИИЛМ, 1993. - 16 с.

11. Лесоводственные требования к технологическим процессам рубок ухода за лесом. - М.: ВНИИЛМ, 1993. $-26 \mathrm{c}$.

12. Морозов, Г.Ф. Избранные труды / Г.Ф. Морозов. - Т. 2. - М.: Лесная пром-сть, 1971. - 536 с.

13. Писаренко, А.И. Всемирные лесохозяйственные конгрессы: от предыстории ФАО до современных проблем лесного хозяйства: памятные научные записки / А.И. Писаренко. - М., 2016. - 407 с.

14. Писаренко, А.И. Лесное хозяйство России: от пользования к управлению / А.И. Писаренко, В.В. Страхов. - М.: ИД «Юриспруденция», 2004. - 552 с. 
15. Постановление Правительства РФ от 07.10.2020 N 1614 “Об утверждении Правил пожарной безопасности в лесах". URL: http://www.consultant.ru/

16. Постановление Правительства РФ от 09.12.2020 N 2047 “Об утверждении Правил санитарной безопасности в лесах". URL: http://www.consultant.ru/

17. Приказ Минприроды России от 01.12.2020 N 993 “Об утверждении Правил заготовки древесины и особенностей заготовки древесины в лесничествах, указанных в статье 23 Лесного кодекса Российской Федерации” (Зарегистрировано в Минюсте России 18.12.2020 N 61553). URL: http:/www.consultant.ru/

18. Приказ Минприроды России от 04.12.2020 N 1014 “Об утверждении правил лесовосстановления, состава проекта лесовосстановления, порядка разработки проекта лесовосстановления и внесения в него изменений” (Зарегистрировано в Минюсте России 18.12.2020 N 61556). URL: http://www.consultant.ru/

19. Приказ Минприроды России от 29.03.2018 N 122 (ред. от 12.05.2020) “Об утверждении Лесоустроительной инструкции” (Зарегистрировано в Минюсте России 20.04.2018 N 50859). URL: http://www. consultant.ru/

20. Приказ Минприроды России от 30.07.2020 N 534 “Об утверждении Правил ухода за лесами” (Зарегистрировано в Минюсте России 18.12.2020 N 61555). URL: http://www.consultant.ru/

21. Реймерс, Н.Ф. Надежды на выживание человечества: Концептуальная экология / Н.Ф. Реймерс. - М.: ИЦ «Россия молодая» - Экология, 1992. - 367 с.

22. Сеннов, С.Н. Рубки ухода за лесом / С.Н. Сеннов. - М.: Лесная пром-сть, 1977. - 160 с.

23. Ткаченко, М.Е. Общее лесоводство / М.Е. Ткаченко. - М.-Л.: Гослесбумиздат, 1955. - 596 с.

24. Хайретдинов, А.Ф. Рекреационное лесоводство / А.Ф. Хайретдинов, С.И. Конашова. - М.: МГУЛ, 2002. -308 c.

25. Цепляев, В.П. Лесопользование и его народно-хозяйственная и природоохранная роль / В.П. Цепляев / ЦБНТИлесхоз, Обзорная информация, М., 1981, 48 с.

26. Чернова, Е.Б. Интенсивное использование для России: опыт инновационного проекта «Псковский модельный лес» / Е.Б. Чернова. - СПб., 2010. - 208 с.

27. Яницкая, Т. Практическое руководство по выделению лесов высокой природоохранной ценности в России / Т. Яницкая. - М.: Всемирный фонд дикой природы (WWF), 2008. - 136 с.

28. Koch, Niels Elers. Sustainable management of planted forests: some comparisons between Central Europe and the United States / N.E. Koch, J.P. Skovsgaard // New Forests - NEW FOREST. - 1999. - vol. 17. - no. 1. - pp. 11-22.

\section{REFERENCES}

1. Aksenov D., Kobjakov K., Shmatkov N., Jaroshenko A. Konceptual'nye podhody k sozdaniju nacional'nogo lesnogo nasledija Rossijskoj Federacii. Ustojchivoe lesopol'zovanie, 2015, no. 3 (43), pp. 2-8. (In Russian)

2. Aktual'nye voprosy intensifikacii lesopol'zovanija v Rossii. Interv'ju s B. Romanjukom, nauchnym rukovoditelem proekta «Pskovskij model'nyj les» i fonda «Grin Forest». Ustojchivoe lesopol'zovanie. 2011, no. 4 (29), pp. 2-6. (In Russian)

3. Atrohin V.G. Formirovanie vysokoproduktivnyh nasazhdenij. Moscow, 1980, 232 p. (In Russian)

4. Georgievskij N.P. Rubki uhoda za lesom. Moscow, 1957, 142 p. (In Russian)

5. Zheldak V.I. Konceptual'nye voprosy opredelenija soderzhanija i sistematizacii lesovodstvennoj kompleksnoj dostupnosti lesov. Proceedings of the St. Petersburg Research Institute of Forestry, 2021, no. 1, pp. 31-54. (In Russian)

6. Zheldak V.I. Sistemy lesovodstvennyh meroprijatij dlja modelej raznogo rezhima soderzhanija lesov i lesopol'zovanija. Lesotehnicheskij zhurnal, 2017, vol. 8, no. 4 (28), pp. 55-71. (In Russian) 
7. Zheldak V.I., Doroshhenkova Je.V., Sidorenkova E.M., Lipkina T.V., Proka I.Ju. Sistematizacija i uchet faktorov i uslovij dostupnosti lesov dlja osushhestvlenija lesovodstvennyh meroprijatij. Lesohozjajstvennaja informacija, 2021, no. 1. pp. 18-39. (In Russian)

8. Il'ina O., Markovskij A., Pilipenko E.; Rodionov A. Potencial'nye obekty nacional'nogo lesnogo nasledija severa evropejskoj chasti Rossii. Ustojchivoe lesopol'zovanie, 2016, no. 3 (47), pp. 8-15. (In Russian)

9. Lesnoj kodeks Rossijskoj Federacii [Jelektronnyj resurs]: ot 04.12.2006 № 200-FZ (red. ot 30.04.2021). URL: http://www.consultant.ru/. (In Russian)

10. Lesovodstvennye trebovanija $\mathrm{k}$ tehnologicheskim processam lesosechnyh rabot. Moscow, $1993,16 \mathrm{p}$. (In Russian)

11. Lesovodstvennye trebovanija k tehnologicheskim processam rubok uhoda za lesom. Moscow, 1993, 26 p. (In Russian)

12. Morozov G.F. Izbrannye trudy. Moscow, 1971, vol. 2, 536 p. (In Russian)

13. Pisarenko A.I. Vsemirnye lesohozjajstvennye kongressy: ot predistorii FAO do sovremennyh problem lesnogo hozjajstva: pamjatnye nauchnye zapiski. Moscow, 2016, 407 p. (In Russian)

14. Pisarenko A.I., Strahov V.V. Lesnoe hozjajstvo Rossii: ot pol'zovanija k upravleniju. Moscow, 2004, 552 p. (In Russian)

15. Postanovlenie Pravitel'stva Rossijskoj Federacii ot 07.10.2020 N 1614 “Ob utverzhdenii Pravil pozharnoj bezopasnosti v lesah". URL: http:/www.consultant.ru/. (In Russian)

16. Postanovlenie Pravitel'stva Rossijskoj Federacii ot 09.12.2020 N 2047 “Ob utverzhdenii Pravil sanitarnoj bezopasnosti v lesah". URL: http://www.consultant.ru/. (In Russian)

17. Prikaz Minprirody Rossii ot 01.12.2020 N 993 “Ob utverzhdenii Pravil zagotovki drevesiny i osobennostej zagotovki drevesiny v lesnichestvah, ukazannyh v stat'e 23 Lesnogo kodeksa Rossijskoj Federacii”" (Zaregistrirovano v Minjuste Rossii 18.12.2020 N 61553). URL: http://www.consultant.ru/. (In Russian)

18. Prikaz Minprirody Rossii ot 04.12.2020 N 1014 "Ob utverzhdenii Pravil lesovosstanovlenija, sostava proekta lesovosstanovlenija, porjadka razrabotki proekta lesovosstanovlenija i vnesenija v nego izmenenij" (Zaregistrirovano v Minjuste Rossii 18.12.2020 N 61556). URL: http://www.consultant.ru/. (In Russian)

19. Prikaz Minprirody Rossii ot 29.03.2018 N 122 (red. ot 12.05.2020) “Ob utverzhdenii Lesoustroitel'noj instrukcii” (Zaregistrirovano v Minjuste Rossii 20.04.2018 N 50859). URL: http://www.consultant.ru. (In Russian)

20. Prikaz Minprirody Rossii ot 30.07.2020 N 534 “Ob utverzhdenii Pravil uhoda za lesami” (Zaregistrirovano v Minjuste Rossii 18.12.2020 N 61555). URL: http://www.consultant.ru. (In Russian)

21. Rejmers N.F. Nadezhdy na vyzhivanie chelovechestva: Konceptual'naja jekologija. Moscow, 1992, 367 p. (In Russian)

22. Sennov S.N. Rubki uhoda za lesom. Moscow, 1977, 160 p. (In Russian)

23. Tkachenko M.E. Obshhee lesovodstvo. Moscow-Leningrad, 1955, 596 p. (In Russian)

24. Hajretdinov A.F., Konashova S.I. Rekreacionnoe lesovodstvo. Moscow, 2002, 308 p. (In Russian)

25. Cepljaev V.P. Lesopol'zovanie i ego narodno-hozjajstvennaja i prirodoohrannaja rol'. CBNTIleshoz, Obzornaja informacija, Moscow. 1981, 48 p. (In Russian)

26. Chernova E.B. Intensivnoe ispol'zovanie dlja Rossii: opyt innovacionnogo proekta «Pskovskij model'nyj les». Saint Petersburg, 2010, 208 p. (In Russian)

27. Janickaja T. Prakticheskoe rukovodstvo po vydeleniju lesov vysokoj prirodoohrannoj cennosti v Rossii. Moscow, WWF, 2008, 136 p. (In Russian)

28. Koch N.E., Skovsgaard J.P. Sustainable management of planted forests: some comparisons between Central Europe and the United States. New Forests, 1999, vol. 17, no. 1, pp. 11-22. 